\title{
Environmental epigenetics: a role in endocrine disease?
}

\author{
Abby F Fleisch, Robert $O$ Wright $^{1}$ and Andrea A Baccarelli ${ }^{1}$ \\ Departments of Endocrinology and Health Services Research, Children's Hospital Boston, 300 Longwood Avenue, Boston, Massachusetts 02115, USA \\ ${ }^{1}$ Department of Environmental Health, Harvard School of Public Health, Boston, Massachusetts, USA \\ (Correspondence should be addressed to A F Fleisch; Email: abby.fleisch@ childrens.harvard.edu)
}

\begin{abstract}
Endocrine disrupting chemicals that are structurally similar to steroid or amine hormones have the potential to mimic endocrine endpoints at the receptor level. However, more recently, epigenetic-induced alteration in gene expression has emerged as an alternative way in which environmental compounds may exert endocrine effects. We review concepts related to environmental epigenetics and relevance for endocrinology through three broad examples: 1) effect of early-life nutritional exposures on future obesity and insulin resistance, 2) effect of lifetime environmental exposures such as ionizing radiation on endocrine cancer risk, and 3) potential for compounds previously classified as endocrine disrupting to additionally or alternatively exert effects through epigenetic mechanisms. The field of environmental epigenetics is still nascent, and additional studies are needed to confirm and reinforce data derived from animal models and preliminary human studies. Current evidence suggests that environmental exposures may significantly impact expression of endocrine-related genes and thereby affect clinical endocrine outcomes.
\end{abstract}

Journal of Molecular Endocrinology (2012) 49, R61-R67

\section{Introduction}

In the 1970s, diethylstilbestrol (DES), an estrogen agonist used to prevent miscarriages, was associated with vaginal clear-cell adenocarcinoma in adult female offspring exposed in utero (Robboy et al. 1977). Mothers who took DES, however, did not appear to be at increased risk for this adenocarcinoma, suggesting that in utero programming may be a mechanism for this observation. Since then, interest in studying the endocrine effects of exogenous agents, and their role in epigenetic programming, has increased dramatically.

Exogenous compounds that alter 'hormonal and homeostatic systems' (i.e. endocrine endpoints) have been termed 'endocrine disrupting chemicals' and were officially recognized in an Endocrine Society statement in 2009 (Diamanti-Kandarakis et al. 2009). The majority of currently identified endocrine disruptors are synthetic industrial chemicals rather than drugs. In the USA, although the Toxic Substances Control Act (TSCA) of 1976 provides a legislative framework to limit the spread of toxic chemicals, companies are not required to perform monitoring for adverse health effects of product chemicals. Toxicity is typically discovered only after the product is widely used. For this reason, many chemicals with suspected or even confirmed endocrine disruption properties are in current daily use.

Many endocrine disrupting chemicals have structural similarity to steroid or amine hormones. Acting as ligands, they can either activate or antagonize the hormone's receptor, leading to altered endocrine endpoints (Diamanti-Kandarakis et al. 2009). However, more recently, the classification of endocrine disrupting chemicals has expanded. Agents such as heavy metals that do not act directly on steroid receptors have been shown to alter hormone metabolism via epigenetic alterations. Also, compounds such as DES that are structurally similar to hormones (Fig. 1) may induce epigenetic changes through interaction with hormone receptors.

\section{What is epigenetics?}

Epigenetics is defined as changes in gene expression that occur without changes in DNA sequence (Wolffe \& Guschin 2000) and can be transmitted through mitosis and/or meiosis. Given that all cells in the human body contain the same DNA sequence, epigenetics can be thought of as those processes that regulate gene expression in a given cell leading to its cellular phenotype, a definition first proposed by 


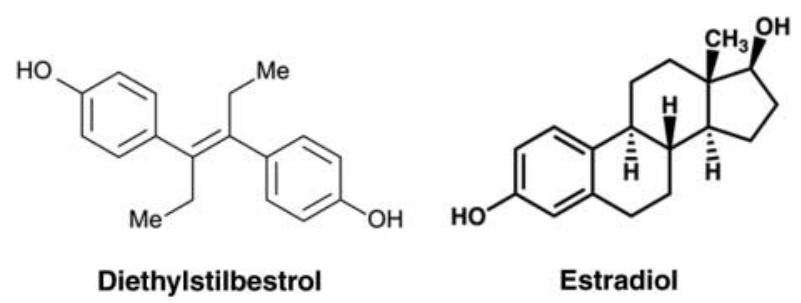

Figure 1 Many endocrine disrupting chemicals, such as DES, have structural similarity to steroid hormones, such as estrogen.

Waddington (1942). One of the more intriguing facets of epigenetics is the responsiveness of many epigenetic marks to environmental factors.

The hereditary component of complex, multifactorial processes such as obesity (Lindgren et al. 2009), diabetes (Voight et al. 2010, Schafer et al. 2011), osteoporosis (Duncan et al. 2011), and pubertal timing (He et al. 2009, Perry et al. 2009) cannot be fully explained by DNA sequence alone. Epigenetics offers a complementary mechanism for heredity that is independent of DNA sequence variation.

Epigenetics involves several types of 'marks' added to either DNA or chromatin leading to transient or persistent changes in gene transcription. Each organism has a unique epigenetic signature that is partially inherited and partially created in utero and continues to be modified throughout adult life. Epigenetic marks may arise from environmental exposures that in turn interact with the genotype to produce changes in gene expression, or epigenetics may explain health outcomes independent of genotype as these marks alone can either turn off or turn on gene expression, functioning as an 'epimutation'. Two of the most widely studied epigenetic changes are DNA methylation and histone modifications.

\section{DNA methylation}

DNA methylation is the addition of a methyl group to a cytosine (C) nucleotide at position 5 and typically occurs when a cytosine is positioned next to a guanine (G). Phosphates (P) link nucleosides in DNA, and, thus, this particular arrangement is termed a $\mathrm{CpG}$ dinucleotide. Regions of the genome dense in $\mathrm{CpG}$ dinucleotides are termed $\mathrm{CpG}$ islands. Although CpG islands have the potential for methylation and are frequently overrepresented at gene promoters, the majority of the time, they are not methylated (Jirtle \& Skinner 2007). Regions with lower CpG density bordering the $\mathrm{CpG}$ islands are termed $\mathrm{CpG}$ shores and have been proposed to occur with increased frequency in regulatory sites involved in tissue differentiation (Doi et al. 2009).

Tissue-specific methylation of CpG dinucleotides by DNA methyltransferases (DNMTs) can lead to gene silencing (Wolffe \& Matzke 1999, Orphanides \& Reinberg 2002). The simplest way to understand DNA methylation is to think of DNA not as strand but as a coil wrapped tightly around a histone. Methylation leads to gene silencing because it alters DNA's three-dimensional structure such that the coil becomes tighter at the locus corresponding to the promoter region. Within this tightened coil, transcription factors can no longer be recruited to their binding sites. Also, methyl binding proteins (MBPs) can interact with methylated CpGs and actively repress gene transcription (Bird \& Wolffe 1999).

There is evidence that physiological DNMT activity is under hormonal control. For example, DNMT1 and MBP levels vary with menstrual cycle phase and with estrogen and progesterone secretion in endometrial explant tissues (van Kaam et al. 2011). Thus, based on their analogy to steroid hormones, some endocrine disrupting compounds have the potential to affect DNMT activity and consequently affect epigenetic marks.

\section{Histone modifications}

Histones are globular proteins around which DNA is packaged to make chromatin. Enzyme modifications such as acetylation and methylation of lysine residues in the amino terminus lead to a histone conformational change. Acetylation leads to increased DNA accessibility, and methylation can either increase or decrease DNA accessibility depending upon the specific type of methylation and histone affected (Yan \& Boyd 2006). DNA methylation and histone modification often work in tandem, as MBPs recruited by DNA methylation may exert their effects through recruitment of histone deacetylases resulting in chromatin condensation and transcriptional inactivation (Jones et al. 1998, Nan et al. 1998).

\section{Epigenetic reprogramming and inheritance}

Epigenetic patterns undergo erasure and reprogramming two times during the human life cycle. One important result of epigenetic reprogramming is the correct establishment of imprinting at sites with allele-specific methylation. Independent of gender, human adult somatic cells contain one haploid set of chromosomes inherited from the mother that carry female-specific imprints, and a second haploid set of chromosomes inherited from the father that carry malespecific imprints. The first phase of erasure and reprogramming occurs during gametogenesis. In the primordial germline, DNA methylation - including methylation at imprinted loci - is erased and later reestablished. At imprinted loci, DNA methylation is reprogrammed so that it will take female-specific 
imprints in oocytes and male-specific imprints in spermatozoa. The second phase of epigenetic erasure and reprogramming occurs during pre-implantation when the genome, with the possible exception of imprinted genes and some retrotransposons, becomes demethylated. After implantation, DNA methylation is restored de novo and rapidly acquires cell lineagespecific patterns to drive cell differentiation. This is the basis for the tissue-specific gene methylation pattern seen after birth and through adulthood. (Reik et al. 2001, Shi \& Wu 2009, Perera \& Herbstman 2011). Folate and vitamin B12 serve as exogenous methyl donors, and their influence on DNA methylation during the in utero time period will be discussed in more detail later in this manuscript.

The prenatal erasure and reprogramming of DNA methylation patterns makes the in utero time period a window of potential vulnerability for epigenetic dysregulation from environmental exposures. This is particularly relevant in endocrinology where there is burgeoning evidence that the fetal environment may program adult outcomes such as obesity and type 2 diabetes mellitus (Law et al. 1992, Stocker et al. 2005).

Other potential vulnerable windows for epigenetic dysregulation that might affect endocrine systems include puberty, during which time there is an overall rapid increase in DNA turnover and cell growth, as well as old age, which has been associated with progressive age-related changes in DNA methylation (Bjornsson et al. 2008; Fig. 2).

\section{Epigene-environment interaction}

Epigenetic dysregulation can result from environmental exposures including dietary factors, physical activity, social stressors, and environmental toxicants (Mathers et al. 2010, Alegria-Torres et al. 2011). However, there is a paucity of human studies that document the causal pathway from environmental exposure to epigenetic modification to clinical outcome (Fig. 3).

We have chosen to demonstrate these themes by reviewing three broad examples where environmental epigenetics has impacted endocrinology. These include 1) effect of early-life nutritional exposures on future obesity and insulin resistance, 2) effect of lifetime environmental exposures such as ionizing radiation on endocrine cancer risk, and 3) potential for endocrine disrupting compounds to affect endocrine endpoints through epigenetic modifications. We review available data and suggest avenues for future research.

\section{Nutritional status and epigenetic changes}

Poor nutrition during pregnancy has been associated with DNA hypomethylation in offspring, which may result from a decrease in dietary sources of methyl group donors such as folate, methionine, and choline in conjunction with decreased availability of $\mathrm{B}$ vitamins (B2, B6, and B12; Mathers et al. 2010). Plasma homocysteine level, an inverse marker of folate

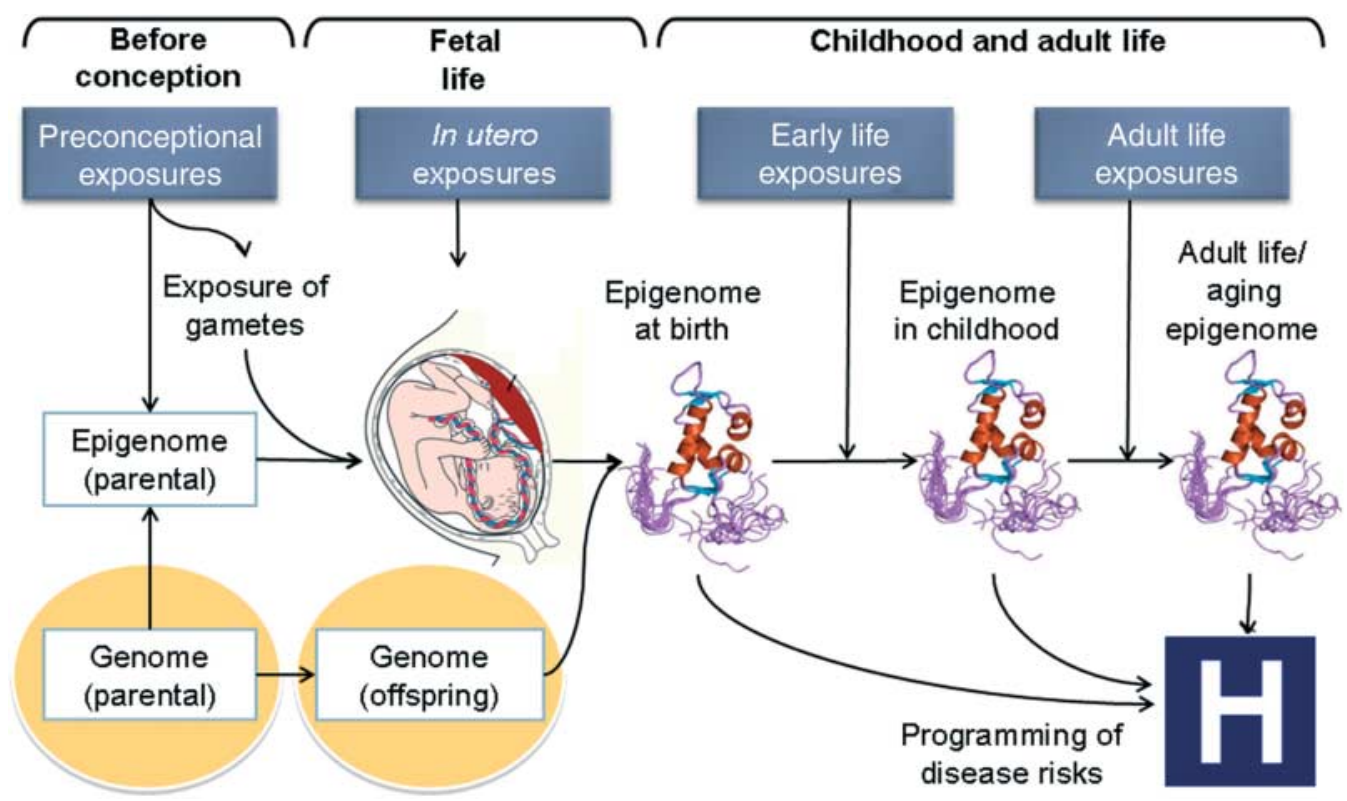

Figure 2 Exposures that occur preconceptionally, in utero, in early life and in adult life may result in epigenetic dysregulation. 


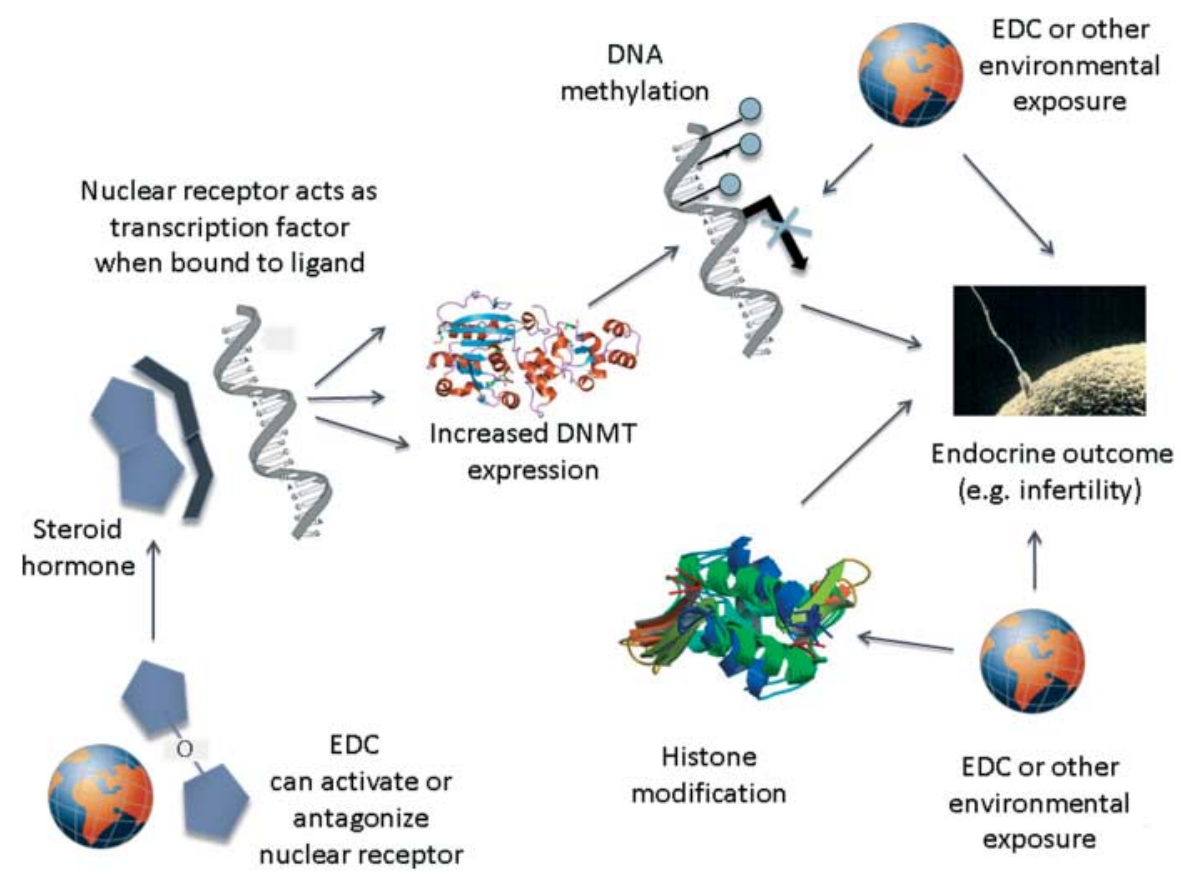

Figure 3 There are multiple potential causal pathways through which an environmental exposure may lead to epigenetic modifications, which may, in turn, impact clinical outcomes. Additional human studies that extend over the entire causal pathway are needed to establish cause-and-effect relationships between exposures and outcomes. EDC, endocrine disrupting compound.

supplementation, has been associated with LINE-1 hypomethylation, gene-specific CpG island methylation patterns, and lower birthweight percentile (Fryer et al. 2009, 2011). Also, offspring of humans exposed to famine in early gestation had hypomethylation of the imprinted IGF2 gene compared to unexposed siblings (Heijmans et al. 2008). Parental overfeeding has also been associated with epigenetic modifications in offspring. In humans, paternal insulin resistance, presumably a result of overeating and obesity, was associated with low infant birth weight and increased risk of diabetes in offspring (Lindsay et al. 2000, Hypponen et al. 2003). Similarly, in rodents, female offspring of high-fat diet (HFD) fathers had lower birth weight and developed glucose intolerance, impaired insulin secretion, and decreased pancreatic islet and $\beta$-cell mass compared with control offspring. Ill3ra2, part of the Jak-Stat signaling pathway, was hypomethylated and upregulated in HFD offspring, suggesting that a HFD may have affected the epigenetic profile of the paternal germ cells ( $\mathrm{Ng}$ et al. 2010).

More recently, in a related study in humans, hypermethylation of the $R X R A$ gene in umbilical cord tissue was associated with lower maternal carbohydrate intake during early pregnancy and later childhood adiposity. RXRA may be involved in insulin sensitivity, adipogenesis, and fat metabolism based on its interaction with PPARG when serving as a transcription factor (Godfrey et al. 2011). These rodent and human studies suggest that parental nutritional status affects the DNA methylation profile and subsequent obesity and insulin resistance in offspring.

\section{Epigenetics and endocrine cancers}

Abundant literature exists linking environmentally induced epigenetic modifications to tumor formation and progression in non-endocrine cancers through altered expression of tumor suppressor genes and proto-oncogenes. For example, benzene exposure has been associated with increased risk of acute myelogenous leukemia (AML; 2005). Individuals with higher than average benzene exposure had a significant reduction in methylation of selected genomic repetitive elements, in conjunction with hypermethylation of tumor suppressor gene $p 15(C D K N 2 B)$ and hypomethylation of the MAGE1 (MAGEA1) gene, suggesting epigenetic modification as a possible pathogenic mechanism (Bollati et al. 2007).

With regard to endocrine-related cancers, epigenetic modifications have also been implicated in thyroid carcinoma via hypermethylation and inactivation of tumor suppressor genes including cyclin-dependent kinase inhibitor p16INK4A (CDKN2A), microtubule stabilizer RASSF1A, GTPase-activating protein RAP1GAP, and PI3K/Akt pathway modulator PTEN (Russo et al. 2011). The PTEN promoter is 
hypermethylated in $50 \%$ of papillary carcinomas and almost $100 \%$ of follicular carcinomas, which is notable because a deleterious mutation in this gene causes PTEN hamartoma tumor syndrome leading to increased risk of papillary and thyroid carcinomas (Hobert \& Eng 2009). As far as a potential environmental trigger for this epigenetic profile, ionizing radiation exposure has traditionally been thought to increase risk of thyroid cancer as a result of DNA mutagenesis, for example, through RET/PTC rearrangements (Caudill et al. 2005, Christodouleas et al. 2011). However, ionizing radiation has also been associated with global DNA hypomethylation that may be genotype specific (Giotopoulos et al. 2006) and that even occurs in cells not directly irradiated (Tamminga et al. 2008). Prior ionizing radiation has also been associated with gene-specific hypermethylation in cancer patients (Figueroa et al. 2009, Bennett et al. 2010, Mathers et al. 2010). Additional research is needed to establish whether ionizing radiation leads to specific epigenetic changes seen in thyroid carcinoma and subsequent thyroid carcinoma development.

Pituitary adenomas have also been associated with hypermethylation-related silencing of tumor suppressor genes such as $R B 1$ and cyclin-dependent kinase inhibitors $p 15$ and $p 16$ (reviewed in Vandeva et al. (2010)). In some studies, GH-secreting adenomas have resulted in tissue-specific loss of imprinting at the paternal stimulatory G-protein allele, which leads to increased expression of $G N A S$ and constitutive activation of adenylyl cyclase (Hayward et al. 2001, reviewed in Mantovani et al. (2010)). As imprinting is an early embryonic process, in utero exposure may be responsible for dysregulated imprinting and subsequent development of GH-secreting adenomas; however, this has not yet been evaluated.

\section{Endocrine disruptors and epigenetics}

A growing number of animal models have linked prenatal endocrine disruptor exposure to offspring epigenetic modifications. Bisphenol A (BPA), a synthetic chemical and weak estrogen agonist found in food and beverage containers (Le et al. 2008), baby bottles (Nam et al. 2010), and dental materials (Fleisch et al. 2010), induced hypomethylation and increased expression of the Agouti gene in prenatally exposed mice leading to yellow rather than brown fur, as well as obesity, diabetes, and tumorigenesis (Dolinoy 2008). Furthermore, rodent mothers with the agouti phenotype were more likely to have offspring with that phenotype in the second generation. This important study serves as proof of principle that prenatal exposure to synthetic estrogen agonists such as BPA can affect the epigenome and thereby lead to endocrinological sequelae.
DES, an estrogen agonist found to cause vaginal clear-cell adenocarcinoma in the female offspring of users, has been associated with epigenetic modifications in offspring uterine tissues. Specifically, in mouse models of prenatal DES exposure and resultant genital tract neoplasia, hypomethylation occurred along with increased uterine expression of estrogensensitive $L T F$ and proto-oncogenes including EGF and SRF (Nelson et al. 1994, Falck \& Forsberg 1996, Li et al. 1997).

Exposure to vinclozolin, a fungicide and antiandrogen, during embryogenesis decreased adult sperm motility and concentration and increased the rate of kidney and prostate disease, immune system abnormalities, hypercholesterolemia, and tumorigenesis in rat first-generation male offspring. This phenotype was transferred through four generations (F1-F4) of male offspring and was associated with alterations in the sperm methylation profile of the F1-F3 generations (Anway et al. 2005). This is one of the first studies to suggest the potential for transgenerational inheritance of epigenetic marks presumably resulting, in this case, from incomplete erasure of epigenetic marks during gametogenesis. However, similar studies attempting to replicate the above findings in vinclozolin-exposed mice demonstrated changes in sperm methylation profile in the F1 and F2, but not the F3 generation (Schneider et al. 2008, Inawaka et al. 2009, Stouder \& Paoloni-Giacobino 2010), suggesting that the phenotype of the F2 generation may be due to exposure of the F1 germline to the maternal environment rather than true transgenerational inheritance.

\section{Future directions}

Environmental epigenetics offers several clear research opportunities, particularly as it relates to endocrinology, including the following:

- Human studies of fetal epigenetic vulnerability to environmental exposures at physiologically relevant doses will confirm existing animal models.

- Human observational studies able to show the relationship from exposure to epigenetic modification to outcome over a life span will be required to differentiate causality from mere association.

- Additional endocrine tissue- and gene-specific studies of epigenetic modifications will further delineate causality.

- Finally, integrated teamwork including clinical endocrinologists, environmental toxicologists, and epidemiologists will strengthen study design and thereby lead to heightened understanding of the impact of environmental epigenetics on endocrinology. 


\section{Conclusions}

Although the field of environmental epigenetics is just moving out of its infancy, it has already begun to demonstrate the breadth of potential impact of environmental exposures on the expression of endocrine-related genes. These results not only suggest the need for increased biomonitoring of synthetic compounds, but also point out specific windows of human susceptibility as well as potential mechanisms that could represent the substrate for future preventive interventions.

\section{Declaration of interest}

The authors declare that there is no conflict of interest that could be perceived as prejudicing the impartiality of the research reported.

\section{Funding}

The authors have received support from the following grants from the US National Institutes of Health: P30ES000002, R21ES019773, R21ES020010, R01ES020268, R01ES013744, and P42ES016454, and have received support from the following grant from AHRQ: T32 HS00063.

\section{References}

Proceedings of the International Symposium on Recent Advances in Benzene Toxicity, Munich, Germany, 9-12 October 2004 Chemico-Biological Interactions 153-1542005 1270

Alegria-Torres JA, Baccarelli A \& Bollati V 2011 Epigenetics and lifestyle. Epigenomics 3 267-277. (doi:10.2217/epi.11.22)

Anway MD, Cupp AS, Uzumcu M \& Skinner MK 2005 Epigenetic transgenerational actions of endocrine disruptors and male fertility. Science 308 1466-1469. (doi:10.1126/science.1108190)

Bennett KL, Lee W, Lamarre E, Zhang X, Seth R, Scharpf J, Hunt J \& Eng C 2010 HPV status-independent association of alcohol and tobacco exposure or prior radiation therapy with promoter methylation of FUSSEL18, EBF3, IRX1, and SEPT9, but not SLC5A8, in head and neck squamous cell carcinomas. Genes, Chromosomes E Cancer 49 319-326.

Bird AP \& Wolffe AP 1999 Methylation-induced repression - belts, braces, and chromatin. Cell 99 451-454. (doi:10.1016/S00928674(00)81532-9)

Bjornsson HT, Sigurdsson MI, Fallin MD, Irizarry RA, Aspelund T, Cui H, Yu W, Rongione MA, Ekstrom TJ, Harris TB et al. 2008 Intra-individual change over time in DNA methylation with familial clustering. Journal of the American Medical Association 299 2877-2883. (doi:10.1001/jama.299.24.2877)

Bollati V, Baccarelli A, Hou L, Bonzini M, Fustinoni S, Cavallo D, Byun HM, Jiang J, Marinelli B, Pesatori AC et al. 2007 Changes in DNA methylation patterns in subjects exposed to low-dose benzene. Cancer Research 67 876-880. (doi:10.1158/0008-5472. CAN-06-2995)

Caudill CM, Zhu Z, Ciampi R, Stringer JR \& Nikiforov YE 2005 Dose-dependent generation of RET/PTC in human thyroid cells after in vitro exposure to gamma-radiation: a model of carcinogenic chromosomal rearrangement induced by ionizing radiation. Journal of Clinical Endocrinology and Metabolism 90 2364-2369. (doi:10.1210/jc.2004-1811)
Christodouleas JP, Forrest RD, Ainsley CG, Tochner Z, Hahn SM \& Glatstein E 2011 Short-term and long-term health risks of nuclear-power-plant accidents. New England Journal of Medicine $\mathbf{3 6 4}$ 2334-2341. (doi:10.1056/NEJMra1103676)

Diamanti-Kandarakis E, Bourguignon JP, Giudice LC, Hauser R, Prins GS, Soto AM, Zoeller RT \& Gore AC 2009 Endocrinedisrupting chemicals: an Endocrine Society scientific statement. Endocrine Reviews 30 293-342. (doi:10.1210/er.2009-0002)

Doi A, Park IH, Wen B, Murakami P, Aryee MJ, Irizarry R, Herb B, Ladd-Acosta C, Rho J, Loewer S et al. 2009 Differential methylation of tissue- and cancer-specific CpG island shores distinguishes human induced pluripotent stem cells, embryonic stem cells and fibroblasts. Nature Genetics 41 1350-1353. (doi:10.1038/ng.471)

Dolinoy DC 2008 The agouti mouse model: an epigenetic biosensor for nutritional and environmental alterations on the fetal epigenome. Nutrition Reviews 66 (Suppl 1) S7-S11. (doi:10.1111/ j.1753-4887.2008.00056.x)

Duncan EL, Danoy P, Kemp JP, Leo PJ, McCloskey E, Nicholson GC, Eastell R, Prince RL, Eisman JA, Jones G et al. 2011 Genome-wide association study using extreme truncate selection identifies novel genes affecting bone mineral density and fracture risk. PLoS Genetics 7 e1001372. (doi:10.1371/journal.pgen.1001372)

Falck L \& Forsberg JG 1996 Immunohistochemical studies on the expression and estrogen dependency of EGF and its receptor and C-fos proto-oncogene in the uterus and vagina of normal and neonatally estrogen-treated mice. Anatomical Record 245 459-471. (doi:10.1002/(SICI) 1097-0185 (199607) 245:3 < 459::AID-AR2>3.0. $\mathrm{CO} ; 2-\mathrm{N})$

Figueroa ME, Skrabanek L, Li Y, Jiemjit A, Fandy TE, Paietta E, Fernandez H, Tallman MS, Greally JM, Carraway H et al. 2009 MDS and secondary AML display unique patterns and abundance of aberrant DNA methylation. Blood 114 3448-3458. (doi:10.1182/ blood-2009-01-200519)

Fleisch AF, Sheffield PE, Chinn C, Edelstein BL \& Landrigan PJ 2010 Bisphenol A and related compounds in dental materials. Pediatrics 126 760-768. (doi:10.1542/peds.2009-2693)

Fryer AA, Nafee TM, Ismail KM, Carroll WD, Emes RD \& Farrell WE 2009 LINE-1 DNA methylation is inversely correlated with cord plasma homocysteine in man: a preliminary study. Epigenetics 4 394-398. (doi:10.4161/epi.4.6.9766)

Fryer AA, Emes RD, Ismail KM, Haworth KE, Mein C, Carroll WD \& Farrell WE 2011 Quantitative, high-resolution epigenetic profiling of CpG loci identifies associations with cord blood plasma homocysteine and birth weight in humans. Epigenetics 6 86-94. (doi:10.4161/epi.6.1.13392)

Giotopoulos G, McCormick C, Cole C, Zanker A, Jawad M, Brown R \& Plumb M 2006 DNA methylation during mouse hemopoietic differentiation and radiation-induced leukemia. Experimental Hematology 34 1462-1470. (doi:10.1016/j.exphem.2006.06.008)

Godfrey KM, Sheppard A, Gluckman PD, Lillycrop KA, Burdge GC, McLean C, Rodford J, Slater-Jefferies JL, Garratt E, Crozier SR et al. 2011 Epigenetic gene promoter methylation at birth is associated with child's later adiposity. Diabetes 60 1528-1534. (doi:10.2337/ db10-0979)

Hayward BE, Barlier A, Korbonits M, Grossman AB, Jacquet P, Enjalbert A \& Bonthron DT 2001 Imprinting of the G(s)alpha gene GNAS1 in the pathogenesis of acromegaly. Journal of Clinical Investigation 107 R31-R36. (doi:10.1172/JCI11887)

He C, Kraft P, Chen C, Buring JE, Pare G, Hankinson SE, Chanock SJ, Ridker PM, Hunter DJ \& Chasman DI 2009 Genome-wide association studies identify loci associated with age at menarche and age at natural menopause. Nature Genetics 41 724-728. (doi:10.1038/ng.385)

Heijmans BT, Tobi EW, Stein AD, Putter H, Blauw GJ, Susser ES, Slagboom PE \& Lumey LH 2008 Persistent epigenetic differences associated with prenatal exposure to famine in humans. PNAS 105 17046-17049. (doi:10.1073/pnas.0806560105) 
Hobert JA \& Eng C 2009 PTEN hamartoma tumor syndrome: an overview. Genetics in Medicine 11 687-694. (doi:10.1097/GIM. 0b013e3181ac9aea)

Hypponen E, Smith GD \& Power C 2003 Parental diabetes and birth weight of offspring: intergenerational cohort study. BMJ326 19-20. (doi:10.1136/bmj.326.7379.19)

Inawaka K, Kawabe M, Takahashi S, Doi Y, Tomigahara Y, Tarui H, Abe J, Kawamura S \& Shirai T 2009 Maternal exposure to antiandrogenic compounds, vinclozolin, flutamide and procymidone, has no effects on spermatogenesis and DNA methylation in male rats of subsequent generations. Toxicology and Applied Pharmacology 237 178-187. (doi:10.1016/j.taap.2009.03.004)

Jirtle RL \& Skinner MK 2007 Environmental epigenomics and disease susceptibility. Nature Reviews. Genetics 8 253-262. (doi:10.1038/ nrg2045)

Jones PL, Veenstra GJ, Wade PA, Vermaak D, Kass SU, Landsberger N, Strouboulis J \& Wolffe AP 1998 Methylated DNA and MeCP2 recruit histone deacetylase to repress transcription. Nature Genetics 19 187-191. (doi:10.1038/561)

van Kaam KJ, Delvoux B, Romano A, D'Hooghe T, Dunselman GA \& Groothuis PG 2011 Deoxyribonucleic acid methyltransferases and methyl-CpG-binding domain proteins in human endometrium and endometriosis. Fertility and Sterility 95 1421-1427. (doi:10.1016/ j.fertnstert.2011.01.031)

Law CM, Barker DJ, Osmond C, Fall CH \& Simmonds SJ 1992 Early growth and abdominal fatness in adult life. Journal of Epidemiology and Community Health 46 184-186. (doi:10.1136/jech. 46.3.184)

Le HH, Carlson EM, Chua JP \& Belcher SM 2008 Bisphenol A is released from polycarbonate drinking bottles and mimics the neurotoxic actions of estrogen in developing cerebellar neurons Toxicology Letters 176 149-156. (doi:10.1016/j.toxlet.2007.11.001)

Li S, Washburn KA, Moore R, Uno T, Teng C, Newbold RR, McLachlan JA \& Negishi M 1997 Developmental exposure to diethylstilbestrol elicits demethylation of estrogen-responsive lactoferrin gene in mouse uterus. Cancer Research 57 4356-4359.

Lindgren CM, Heid IM, Randall JC, Lamina C, Steinthorsdottir V, Qi L, Speliotes EK, Thorleifsson G, Willer CJ, Herrera BM et al. 2009 Genome-wide association scan meta-analysis identifies three loci influencing adiposity and fat distribution. PLoS Genetics 5 e1000508. (doi:10.1371/journal.pgen.1000508)

Lindsay RS, Dabelea D, Roumain J, Hanson RL, Bennett PH \& Knowler WC 2000 Type 2 diabetes and low birth weight: the role of paternal inheritance in the association of low birth weight and diabetes. Diabetes 49 445-449. (doi:10.2337/diabetes. 49.3.445)

Mantovani G, Lania AG \& Spada A 2010 GNAS imprinting and pituitary tumors. Molecular and Cellular Endocrinology 326 15-18. (doi:10.1016/j.mce.2010.04.009)

Mathers JC, Strathdee G \& Relton CL 2010 Induction of epigenetic alterations by dietary and other environmental factors. Advances in Genetics 71 3-39. (doi:10.1016/B978-0-12-380864-6.00001-8)

Nam SH, Seo YM \& Kim MG 2010 Bisphenol A migration from polycarbonate baby bottle with repeated use. Chemosphere 79 949-952. (doi:10.1016/j.chemosphere.2010.02.049)

Nan X, Ng HH, Johnson CA, Laherty CD, Turner BM, Eisenman RN \& Bird A 1998 Transcriptional repression by the methyl-CpG-binding protein MeCP2 involves a histone deacetylase complex. Nature 393 386-389. (doi:10.1038/30764)

Nelson KG, Sakai Y, Eitzman B, Steed T \& McLachlan J 1994 Exposure to diethylstilbestrol during a critical developmental period of the mouse reproductive tract leads to persistent induction of two estrogenregulated genes. Cell Growth E Differentiation 5 595-606.

Ng SF, Lin RC, Laybutt DR, Barres R, Owens JA \& Morris MJ 2010 Chronic high-fat diet in fathers programs $\beta$-cell dysfunction in female rat offspring. Nature 467 963-966. (doi:10.1038/ nature09491)
Orphanides G \& Reinberg D 2002 A unified theory of gene expression Cell 108 439-451. (doi:10.1016/S0092-8674(02)00655-4)

Perera F \& Herbstman J 2011 Prenatal environmental exposures, epigenetics, and disease. Reproductive Toxicology 31 363-373. (doi:10.1016/j.reprotox.2010.12.055)

Perry JR, Stolk L, Franceschini N, Lunetta KL, Zhai G, McArdle PF, Smith AV, Aspelund T, Bandinelli S, Boerwinkle E et al. 2009 Meta-analysis of genome-wide association data identifies two loci influencing age at menarche. Nature Genetics 41 648-650. (doi:10.1038/ng.386)

Reik W, Dean W \& Walter J 2001 Epigenetic reprogramming in mammalian development. Science 293 1089-1093. (doi:10.1126/ science.1063443)

Robboy SJ, Scully RE, Welch WR \& Herbst AL 1977 Intrauterine diethylstilbestrol exposure and its consequences: pathologic characteristics of vaginal adenosis, clear cell adenocarcinoma, and related lesions. Archives of Pathology $\mathcal{E}$ Laboratory Medicine 101 1-5.

Russo D, Damante G, Puxeddu E, Durante C \& Filetti S 2011 Epigenetics of thyroid cancer and novel therapeutic targets. Journal of Molecular Endocrinology 46 R73-R81. (doi:10.1530/JME$10-0150)$

Schafer SA, Machicao F, Fritsche A, Haring HU \& Kantartzis K 2011 New type 2 diabetes risk genes provide new insights in insulin secretion mechanisms. Diabetes Research and Clinical Practice 93 (Suppl 1) S9-S24. (doi:10.1016/S0168-8227(11)70008-0)

Schneider S, Kaufmann W, Buesen R \& van Ravenzwaay B 2008 Vinclozolin - the lack of a transgenerational effect after oral maternal exposure during organogenesis. Reproductive Toxicology 25 352-360. (doi:10.1016/j.reprotox.2008.04.001)

Shi L \& Wu J 2009 Epigenetic regulation in mammalian preimplantation embryo development. Reproductive Biology and Endocrinology 7 59. (doi:10.1186/1477-7827-7-59)

Stocker CJ, Arch JR \& Cawthorne MA 2005 Fetal origins of insulin resistance and obesity. Proceedings of the Nutrition Society 64 143-151. (doi:10.1079/PNS2005417)

Stouder C \& Paoloni-Giacobino A 2010 Transgenerational effects of the endocrine disruptor vinclozolin on the methylation pattern of imprinted genes in the mouse sperm. Reproduction 139 373-379. (doi:10.1530/REP-09-0340)

Tamminga J, Koturbash I, Baker M, Kutanzi K, Kathiria P, Pogribny IP, Sutherland RJ \& Kovalchuk O 2008 Paternal cranial irradiation induces distant bystander DNA damage in the germline and leads to epigenetic alterations in the offspring. Cell Cycle 7 1238-1245. (doi:10.4161/cc.7.9.5806)

Vandeva S, Jaffrain-Rea ML, Daly AF, Tichomirowa M, Zacharieva S \& Beckers A 2010 The genetics of pituitary adenomas. Best Practice $\mathcal{E}$ Research. Clinical Endocrinology E Metabolism 24 461-476. (doi:10.1016/j.beem.2010.03.001)

Voight BF, Scott LJ, Steinthorsdottir V, Morris AP, Dina C, Welch RP, Zeggini E, Huth C, Aulchenko YS, Thorleifsson G et al. 2010 Twelve type 2 diabetes susceptibility loci identified through large-scale association analysis. Nature Genetics 42 579-589. (doi:10.1038/ng.609)

Waddington C 1942 The epigenome. Endeavour 1 18-20.

Wolffe AP \& Matzke MA 1999 Epigenetics: regulation through repression. Science 286 481-486. (doi:10.1126/science.286.5439.481)

Wolffe AP \& Guschin D 2000 Review: chromatin structural features and targets that regulate transcription. Journal of Structural Biology 129 102-122. (doi:10.1006/jsbi.2000.4217)

Yan C \& Boyd DD 2006 Histone H3 acetylation and H3 K4 methylation define distinct chromatin regions permissive for transgene expression. Molecular and Cellular Biology 26 6357-6371. (doi:10. 1128/MCB.00311-06)

Received in final form 27 June 2012

Accepted 12 July 2012

Made available online as an Accepted Preprint 13 July 2012 